\title{
A Review on Programmable Logical Controller based Multiple Switching System for Electrical Appliances
}

\author{
N.R. Chitragar ${ }^{1}$, Sudhakar .C.J ${ }^{2}$ \\ Assistant Professor, Faculty of Electrical \& Electronics Engineering, Gogte Institute of Technology, Belagavi ${ }^{1,2}$
}

\begin{abstract}
For the smart home control applications, smart switching system is designed. The system uses real time programmable logic controller (PLC) for switching the electrical appliances. Electrical appliance is a part of our daily needs. When such needs are in a very high demand, requirement to access their electrical appliances in a more flexible way and also safer to use is increases. The system is capable of switching any electrical appliances manually, preprogrammed and remotely. The most common practice in our daily life is manual switching. The second method in this system is preprogramming method which allows the users to program the usage of certain electrical appliances in advance or repetitively. Such function can be used on daily, weekly, monthly and even yearly basis based on the requirements of the user. The third method in this system is remote switching where the users are capable of sending Short Messaging System (SMS) to switch ON and OFF their electrical appliances using mobile phones. Global System for Mobile Communication Modulator and Demodulator (GSM Modem) enables SMS commands to be received to the PLC. The applications of technology have seen many new intelligent systems overwriting the conventional method to ease human life in many ways. Many systems are designed to be flexible for the users and enable them to communicate for the latest status of their electrical appliances at any time. Such applications will be practical and benefits for both the domestic and industrial users from various level of electrical applications without boundaries.
\end{abstract}

Keywords: Smart home, smart switching system, intelligent controller, Short Messaging System, PLC.

\section{INTRODUCTION TO THE SMART HOME APPLICATIONS AND ITS REVOLUTION}

The future of mankind is depending on the technology system will not only reduce energy bills, but prolong the growth in line with our daily needs. The rapid growth of life span of the electrical appliances in the long run.

technology helps mankind in many ways and one of the implementation of such technology is smart home system. The revolution in smart home applications creates high potential amount users and now becoming a trend in the current homes.

Generally, smart home is a house that uses information technology to monitor the environment of the house, control of electric appliances and able to communicates with the outer world with some technological assistance [1]. Smart home system offers the prospect of significant improvements in our living standards for all level of users especially the older ones and disables who are reliant heavily on home care. Smart home concentrates and emphasizes on a few aspects such as safety, security, flexibility and comfort of users.

At an increasing rate, people are turning their homes into state-of-the-art machines, complete with switches, sensors, and actuators for many applications within their resources [2]. A smart home is an ordinary house that is embedded with extraordinary gadgets for better applications which increases the living standards of the users.

By utilizing advanced technologies effectively, life is made easier and simpler, besides saving time and energy under the same roof. Smart home ensures the safety and security of the family members. Simplify house chores and tasks which also help in efficient energy management system in the effort to reduce electricity bills. Such a

Automating a domestic home will results in various benefits to the users regardless of time and energy. Smart home technology offers a wide range of different benefits to the consumer from all levels of users and these includes safety and security features whereby centralized control of the home and any time remote access to all applications is a part of the system.

\section{CENTRALIZED CONTROL SYSTEM}

In this decade, tremendous control technologies on electrical switching is being implemented in order to optimize the usage is the ultimate concern for researchers. Very common limitations as time consuming, cost, power consumption and the limitation of the accessibility are the major problems which is faced by the consumer in switching electrical appliances. The basic block diagram of the smart switching system integrated with the conventional switching method is shown in Fig. 1.

PLC based smart home system is a new approach for home electrical automation. The real time control unit creates many extensive utility in various electrical based applications. The flexibleness and wide relevance which can be practiced in industrial sites, hospitals, office lots, apartments and many locations. To provide a proficient and dominant smart home system this is significant and superior devices to enlarge the scope of functions for this module. 


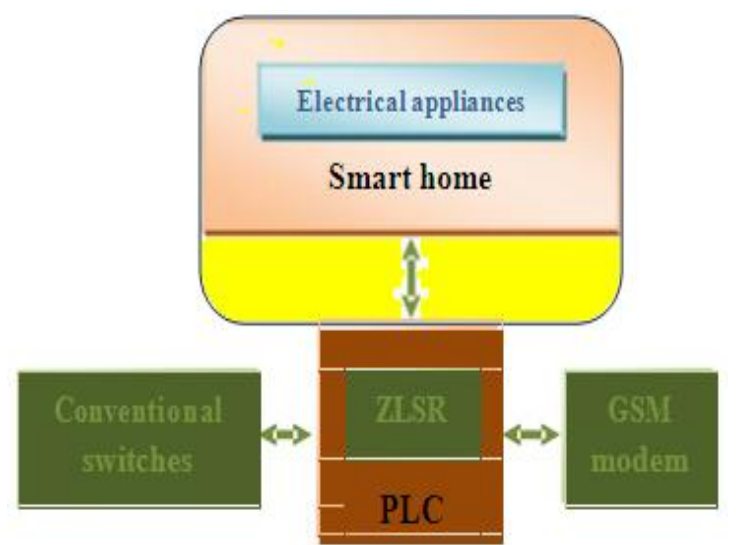

Fig.1. Basic block diagram of the smart switching system

The proposed system uses a PLC as the main control unit and a GSM modem for remote access and control of an electrical appliance via SMS. This system enables the user to correspond with the control unit for preprogrammed and manual switching which eliminate time and energy consumption. On the other hand, this system can be implemented to the smart homes that are aimed to develop a home that offer safety, security and comfort with a modern technology integrated. The PLC as the primary control unit provides reliable electrical switching and also monitoring the status of the electrical appliances. The developed prototype of a smart switching system is shown in Fig. 2.

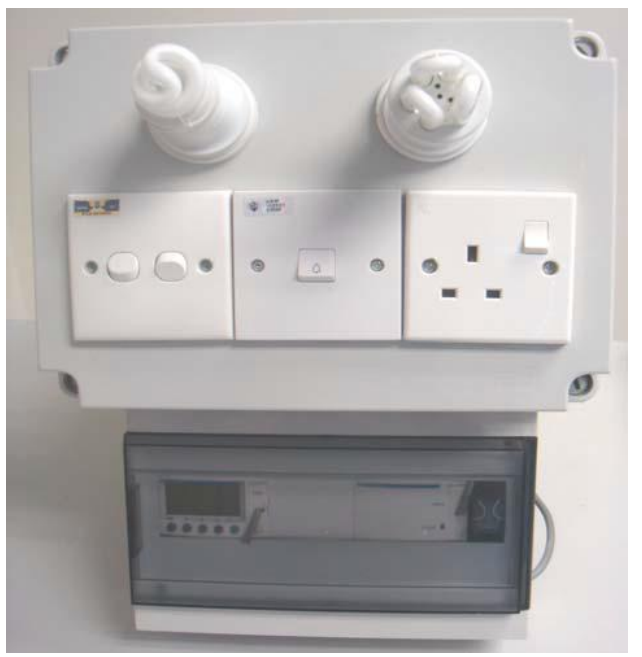

Fig.2. the prototype of a smart switching system

Apart from manual switching and preprogrammed switching is a basic function in the system, state of the art technology enables the end users to control and monitor the entire system remotely via SMS. To accomplish this task, the GSM modem is integrated to the PLC using a communication interface. This entire system enables the end user to interactively communicate with the system at any time [3].

\section{CONTROL COMPONENTS USED IN THE SMART SWITCHING SYSTEM}

\subsection{Real time programmable logic controller}

The Zelio Logic Smart Relay (ZLSR) is the control unit used in the smart switching system. ZLSR compromises the requirements of the smart switching system in supporting with real time control system with the capability of preprogrammed wireless communication alerting system. The ZLSR is an intelligence device which is capable to work without human interventions at all times [4]. The detail block diagram of the smart switching system is shown in Fig. 3.

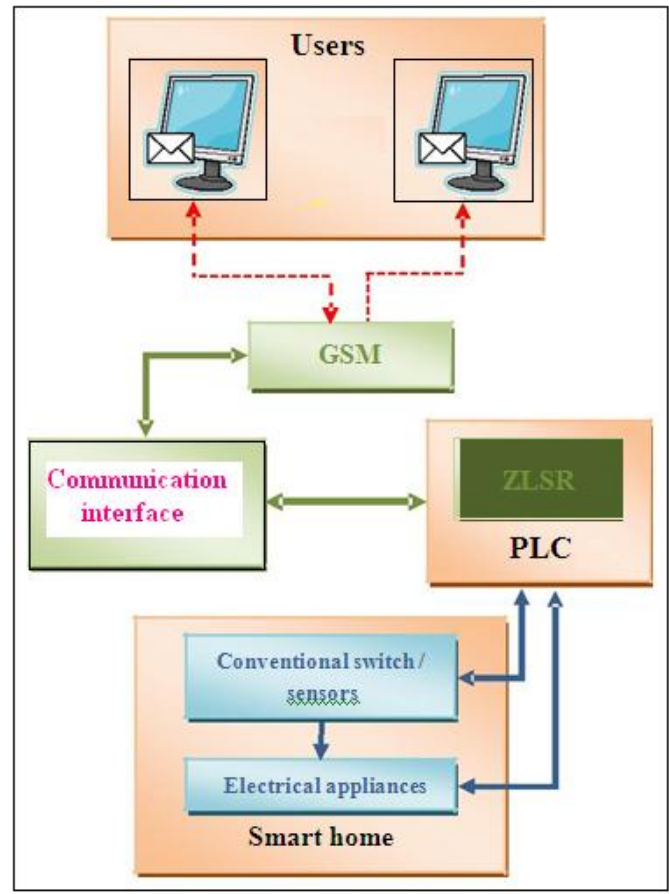

Fig.3. Detail block diagram of the smart switching system

ZLSR is designed to simplify the electrical wiring of intelligent solutions. Its flexibility and its high performance allow users to save significant amounts of time and money in developing an automation system. ZLSR are used in both the industrial and commercial sectors. Their compact size and ease of setting up make them a competitive alternative to solutions for real time control device in various automation systems. The autonomous operating time of the clock, assured by a lithium battery which is up to 10 years ensures the real time of the system is maintained [4].

Since ZLSR is a reliable control unit with the capability to control an extensive range of electronic applications, it seems to be the perfect match to the GSM modem to establish wireless communication for the users. The sensors placed on the mailbox send signals to the ZLSR and the program will generate SMS or email base on the requirements of the users at the event a mail is delivered [5].

\subsection{Communication interface}

The communication interface in the Zelio Logic is designed mainly for monitoring or remote switching which operate without human intervention [6]. The communication range comprises a communication interface connected between a smart relay and a GSM modem, analogue (PSTN), Zelio Soft Com software.

The system communicates with the conventional switches installed on the user's house. Control is achieved by a 
smart relay from the ZLSR via its inputs and outputs. The smart relay is connected via a communication interface to a GSM type modem.

The communication interface allows messages, telephone numbers and call conditions to be stored. In addition, messages are dated and application program comments are stored [4]. The communication interface enables the user to have two way communications with the smart switching system using a GSM modem by sending specific commands to check on their status of electrical appliances at any time as requested by the user.

\subsection{GSM modem}

A GSM modem can be an external modem device, such as the Wavecom FASTRACK GSM modem SR1MOD02 [7]. The simple system works by inserting a GSM sim card (ranging from 012,013,014,016,017, 018 and 019) into this modem. The modem is then connected to an available serial port.

The dedicated GSM modem SR1MOD02 is used as a wireless communication device as the majority of commercially available modems do. A specific contract with the provider, which allows data transmission as required for the smart switching system. The sms and email gateway can simultaneously support multiple modems, provided that the hardware has the available communications port resources.

Text messages saved in the ZLSR will be transmitted to the user's number as assigned in the program. The GSM modem is a device which enables two way communications between the smart switching system and the users [5].

\section{SWITCHING OPERATION}

The system operates based on signals received by switches that are connected to the ZLSR. All the electrical appliances connected to the output of ZLSR will be assigned in the software of ZLSR. Since the output is not directly controlled by ZLSR, the system is capable of switching the electrical appliances manually, in preprogrammed mode and remotely via sms.

The output port of ZLSR is used to switch both DC and AC external relay which is connected to the load. For electrical appliances which require more than $8 \mathrm{amps}$, the external relay is to be replaced as required. The switching option is shown in Fig. 4

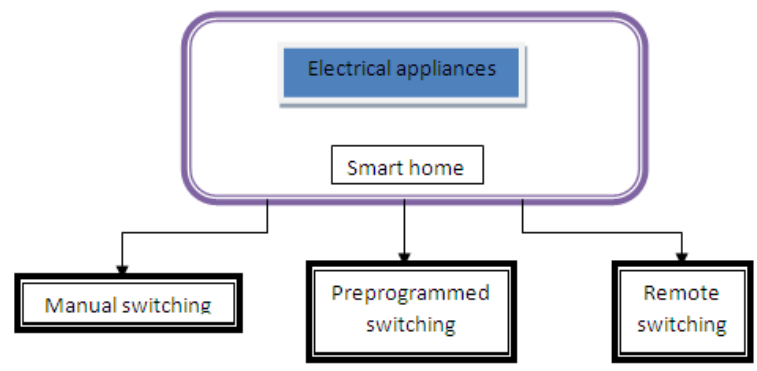

Fig.4. Switching option in the smart switching system

\subsection{Manual switching method}

The manual switching enables the user to interact with the electrical appliances directly. The users can switch $\mathrm{ON}$ or switch OFF the electrical appliances manually using the conventional switches (toggle switch) [8] - [10]. The drawing diagram of the conventional switching method is shown in Fig. 5.

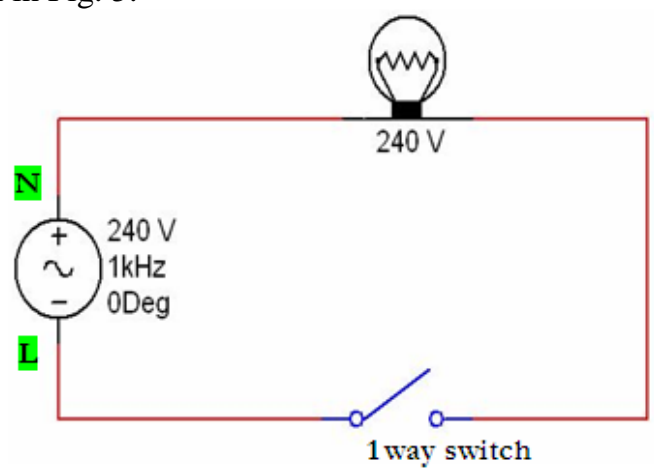

Fig.5. Conventional switching method

In most smart home system, the conventional method of switching is being replaced by the smart switching technique or device. The smart switching system requires an external relay for other switching option with the manual switching method. This smart home system uses two way switches to instead of the current one way switches for other possible switching method available with this system. As usual the users can use this switches to switch ON and switch OFF their electrical appliances at any point of time regardless of the control unit status.

The switching method is not a limitation for other switching method to operate in parallel with the manual switching method. When the conventional switches are used to ON a load manual, it can be switched OFF via SMS commands of based on programmed scheduled [11]. The drawing diagram of the external relay connection with the smart switching system in shown in Fig. 6.

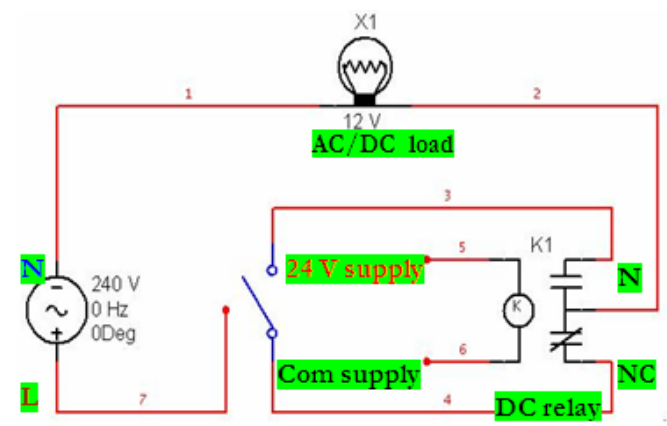

2 way switch

Fig.6. External relay connection to the smart switching system

\subsection{Preprogram switching method}

The preprogrammed switching is done automatically by ZLSR as programmed by the user. ZLSR works according to the time frame specified in the program. This method enables the ZLSR to switch ON the electrical appliances without human intervention with the system. This application is very practical for users which wish to switch ON their electrical appliances for a length of time frequently. This application can be on daily basis, weekly basis and monthly basis [4]. 
The preprogram switching method is not a limitation for other switching operation to interrupt with the same electrical appliances at the same instance. If the preprogram is in $\mathrm{ON}$ mode whereby the load connected to it will be in ON status, the user can switch OFF the same load using conventional method or remote switching method. Such applications help the users to be in control with the system at any time without any restrictions.

The preprogram scheduling system is shown in Fig. 7.

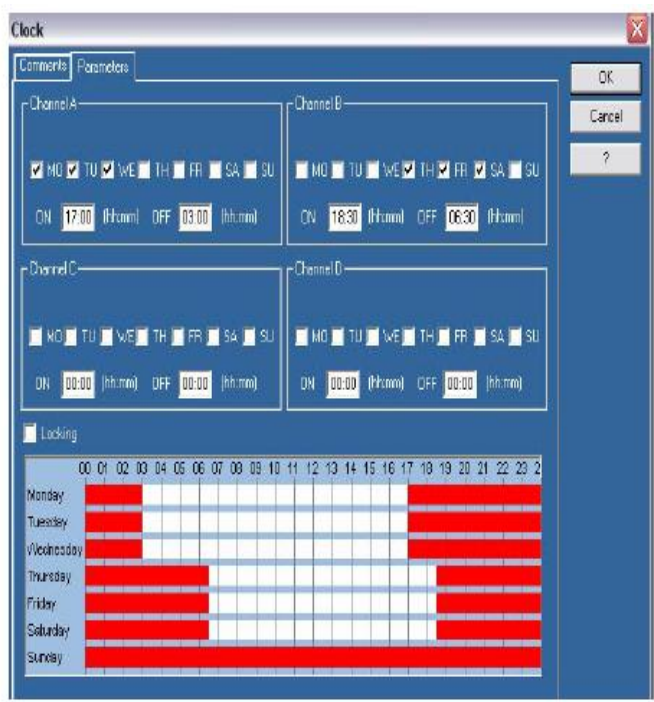

Fig.7. Preprogrammed Schedule Setting in Zelio Soft software

\subsection{Remote switching method}

Remote switching is an alternative method of accessing to the electrical appliances using a hand phone. By sending a command through SMS to ZLSR, the system will be able to react according to the sent commands [4]. This system also enables the users to interact to the system at any time to control and also monitor the status of the respected electrical appliances [4].

A Subscriber Identity Module (SIM) card which is a removable smart card for mobile phone is inserted to the GSM modem. The remote switching is done by the user using a specific messaging command such as " 12345678 ! LIGHT $1=1$ " to turns ON the light number 1 as shown in Fig. 8.
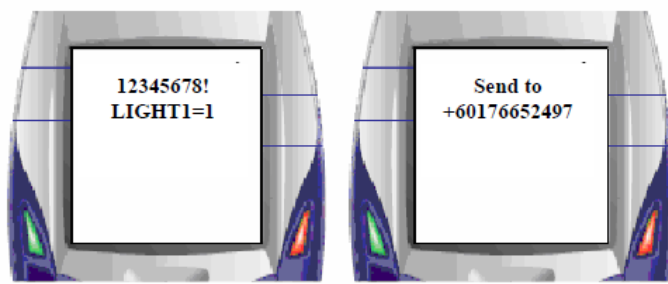

Fig.8. Command for remote switching via SMS

For switching OFF the electrical appliances via remote switching is done by the user using a specific messaging command such as " 12345678 ! LIGHT1 $=0$ " to turns OFF the light number 0 as shown in Fig. 9. The ON and OFF command is the same for all the other electrical appliances. The only difference is the Description or name used to indicate each electrical application [6].

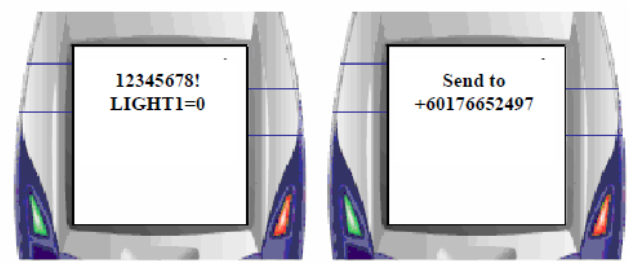

Fig.9. Command for remote switching via SMS

Text "12345678! LIGHT1?" in order to monitor the current status of light 1 as shown in Fig. 10. The 8 digit security code is assigned to the users hand phone number for various functions in the smart switching system [4]. The GSM modem provides high security features whereby only authorized mobile phone users programmed in ZLSR is able to communicate for switching and monitoring purposes. At the same time, the GSM modem can be programmed to alarm multiple users with limited access on the modification of the system and status of the appliances [12].
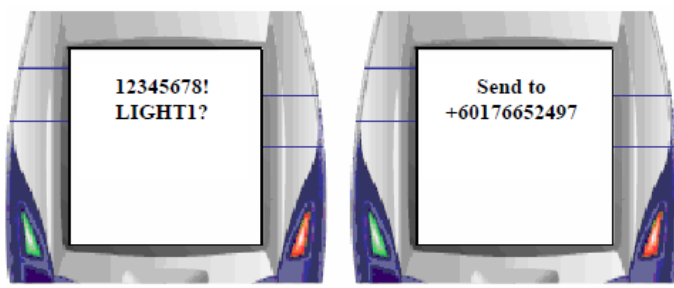

Fig.10. Command for status checking via SMS

\section{ERROR DETECTION SYSTEM}

The Error detection system is integrated with the smart switching system for detecting and alerts the users for any faulty electrical appliances within its connection. The error detection system can be designed and integrated to any load with AC or DC Relays.

External relays connected to the PLC for detection will be active high when device is operating in good condition. At the event the load fail to operate the relay will be low and the PLC will detect the type and which load in the defected one and it will be processed in PLC for alerts system. This is designed in the afford for a safer home environment and as a precaution since a defected load has a higher risk for short circuit if it is turned on for an extensive period. As a result the short circuit from the faulty load will ignite fire. By understating all the possible miseries, the error detection system is implemented into this smart switching system where if there is any faulty load the system will immediately send a signal is sent to the PLC. Based on the signal detection, the PLC will send an alert to the user regarding the defect. Here, the users are recommended to switch OFF their electrical appliances to avoid any consequences. The error detection system is shown Fig. 11.

When the light is switched $\mathrm{ON}$, AC relay will trigger the $24 \mathrm{~V}$ contact from Normally Close (NC) to Normally Open (NO). In the condition if light is faulty, it will not energize the AC relay coil to trigger from NC to NO. When the coil maintain its condition on NO, a signal is sent to the PLC (NO connected to PLC input) to send the alert to user regarding this defect. This is just a sample application 
which is attempted to detect faults in electrical appliances. switching on the electrical appliances based on the Such system can be implemented to various electrical requested by the users via SMS to the system [3], [5], [12]. appliances within the smart switching system.

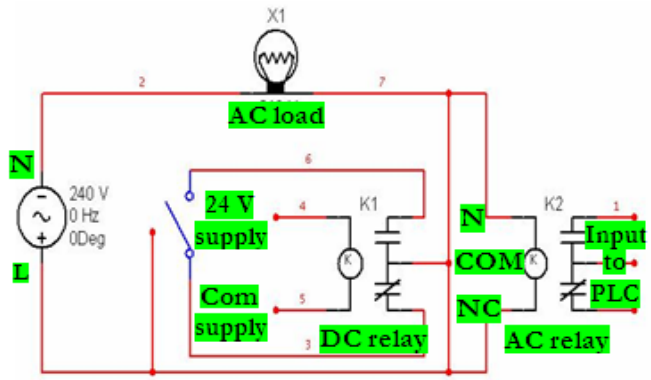

Fig.11. Error detection connection with the smart switching system

\section{POWER FAILURE ALERT SYSTEM}

The power failure alert system is a system which is integrated with the smart switching system to alert the users whenever there is a power failure. A back up battery will power the control unit for this purpose and enables the system alert the users when the system detects power failure. The system is also capable of sending alerts to the users once the power resume back to the normal operation. The power failure detection system is shown in Fig. 12.

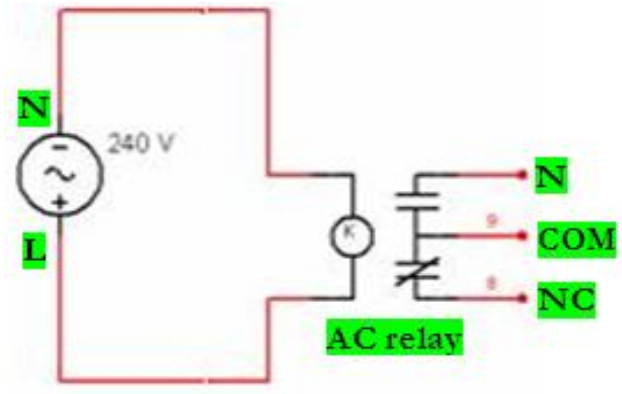

Fig.12. Power failure detection system

An external AC relay will be connected to the AC supply source for this function. The relay will trigger the PLC input at the event of power failure being detected. The smart switching system will authenticate the power failure after a given length of time before sending alerts to the users. Such application will be very useful for business and commercial buildings whereby this enables the users to know the power failure in real time and instantly without fail. The prototype develop can operate with the backup battery for approximately five hours in normal operation mode. With a larger battery capacity the standby duration of the system can be increased.

\section{COMMUNICATION AND SWITCHING ANALYSIS OF THE SYSTEM}

Each system has its downfall or limitations during operations or in the long run [13]. Such limitations can be minimized to the best level to increase the performance and efficiency of a system. In this smart switching system the limitations falls under the wireless communication time and this include the time delay in sending information requested via SMS to the users from the system. Apart from that the system has a delay on performing the
There are a few factors involved in the delay of switching and information reply from the system. The time delay may be due to the poor signal strength from the service provider at a specific location. At certain locations the signal strength of the mobile connection may not be consistent due to the environment conditions. When the system is unable to send information via SMS in such scenario, the system will attempt to resend the SMS again after a short duration of time. The number of attempts that the system will try is based on the users request and this is done while programming the control system. The time study is done for both condition and shown in Table 1 for both receiving and interacting with the users. The second factor is due to the time delay for processing the information or request send by the users to the system. The system requires a minimum time to process the request and also information before action is being taken accordingly. The delay is impossible to be shortening since this is the delay due to the technical operation within the control system. The more request is send by the users, the time delay will also increase accordingly. Most of the time the system will react fast and the request will be performed without fail.

Table 1: Communication duration of system

\begin{tabular}{|c|c|c|}
\hline Destination & $\begin{array}{l}\text { Shortest } \\
\text { duration }\end{array}$ & $\begin{array}{l}\text { Longest } \\
\text { duration }\end{array}$ \\
\hline system(switching) & 20 seconds & 60 seconds \\
\hline $\begin{array}{c}\text { System to user(alert } \\
\text { system) }\end{array}$ & 16 seconds & 45 seconds \\
\hline $\begin{array}{l}\text { User to system to user } \\
\text { (information request) }\end{array}$ & 30 seconds & 60 seconds \\
\hline
\end{tabular}

Apart from the switching delay, the Smart Switching System has a limited input and output ports available to be connected to the electrical appliances. The maximum number of inputs is limited to 24 ports and the output is limited to 16 ports per PLC module. For big number of switching system, more PLC module is required to be connected to the system and this will increase the costing of installation. When high power electrical appliances are connected to the Smart Switching System, additional external relays will be required. The internal relay is rated at 8 amps for each individual output. When the electrical appliances such as the power socket outlets which requires more than 8 amps, an external relay is necessary to support the system.

\section{ADVANTAGE OF SYSTEM}

The new revolution in smart home system especially alerting users on their electrical appliances status is an effective and efficient technique. Instant alerts on faulty electrical appliances or system delivered via sms or email is the most common technology humans are engaged with during working hours and during their leisure time. In addition to that the users are also capable of checking their appliances status or send switching commands just by 
sending a SMS to the control system.

The control system will instantly reply to the users of the current status or perform the requested operation. Weighing the advantages of smart switching system comparing with the conventional switching method available in the market is as shown in Table 2.

Table 2: Factors on mail delivery

\begin{tabular}{|cccc|}
\hline Factors & $\begin{array}{c}\text { Conventional } \\
\text { Switching } \\
\text { system }\end{array}$ & $\begin{array}{c}\text { Smart } \\
\text { home } \\
\text { system }\end{array}$ & $\begin{array}{c}\text { Smart } \\
\text { switching } \\
\text { system }\end{array}$ \\
$\begin{array}{c}\text { Faulty } \\
\text { appliances } \\
\text { alerts } \\
\text { Remote } \\
\text { switching }\end{array}$ & No & No & Instantly \\
$\begin{array}{c}\text { Preprogram } \\
\text { switching } \\
\text { Manual } \\
\text { switching }\end{array}$ & No & Automatic & Automatic \\
$\begin{array}{c}\text { Power failure } \\
\text { alert system }\end{array}$ & No & No & Yes \\
Information \\
request
\end{tabular}

There are three major wireless telecommunication service providers in Malaysia. The information on Table 3 presents the SMS rates for two of the service provider [14].

Table 3: SMS rates in Malaysia

\begin{tabular}{|c|c|c|c|}
\hline $\begin{array}{c}\text { Service } \\
\text { provider }\end{array}$ & $\begin{array}{c}\text { Users account } \\
\text { type }\end{array}$ & $\begin{array}{c}\text { Same } \\
\text { operators }\end{array}$ & $\begin{array}{c}\text { Other } \\
\text { operators }\end{array}$ \\
\hline \multirow{3}{*}{$\begin{array}{c}\text { Company } \\
\text { A }\end{array}$} & Postpaid & RM 0.08 & RM 0.12 \\
\hline & $\begin{array}{c}\text { Prepaid } \\
\text { Postpaid \& }\end{array}$ & RM 0.09 & RM 0.15 \\
\hline & $\begin{array}{l}\text { Prepaid (special } \\
\text { grouping option) }\end{array}$ & RM 0.01 & - \\
\hline \multirow[b]{2}{*}{$\begin{array}{c}\text { Company } \\
\text { B }\end{array}$} & Postpaid & RM 0.10 & RM 0.10 \\
\hline & $\begin{array}{c}\text { Prepaid } \\
\text { Postpaid \& } \\
\text { Prepaid (special } \\
\text { grouping option) }\end{array}$ & RM 0.10 & RM 0.10 \\
\hline
\end{tabular}

Mainly there are two type of users, which is postpaid users and prepaid users where the SMS rates also differ accordingly [8]. Usually if the users send SMS within the same service provider the SMS rates will be cheap comparing to other service provider. The cost for the SMS can also be reduced by engaging the user's mobile number with the system's GSM modem number with the special grouping system offered by the service provider.

\section{CONCLUSION}

A smart home is associated with high rapidly changing technology in this current era. Such application with the home electrical appliances would help the users to save thousands of Ringgit (RM) and ensure a more flexible system without boundaries. Apart from domestic usage, the smart switching system can also be utilized for industrial application. Apart from the savings the system ensures safety for all levels of users.

The system allows the users to switch (ON and OFF) and monitor their electrical appliances by three possible switching methods. The system overwrites the conventional and other smart home system available in the market by integrating all the possible switching method available within its resources. Such practical application enables the users for better options and approach to control and monitor their electrical appliances regardless of location. There are sufficient regular users and awareness behind such applications [14] - [16]. The practicality of this application will results in various benefits to the users from all nature with the implementation of new technology. The goal behind each technology and system is focused to ease human lives in their daily routine. The smart switching system could be a simple solution on the surface but could be an essential application to the mankind in all means.

\section{REFERENCES}

[1] Yuansheng Liu, "Design of the Smart Home based on embedded system", Computer- Aided Industrial Design and Conceptual Design, 17 - 19 Nov 2006.

[2] Gordon Meyer, "Smart Home Hacks, Tips and tools for Automating your House", O 'Reilly, Oct 2004, Page(s): 2-3.

[3] Siva Kumar a/l Subramaniam, Siti Huzaimah binti Husin, Yusmarnita binti Yusop and Abdul Hamid bin Hamidon, 2009, SMS or E-mail alert system for centralize mail compartment, Proceedings of the $8^{\text {th }}$ International Conference on Applications of Electrical Engineering, 30 April - 2 May 2009, Page(s): 52-56.

[4] Zelio Logic 2 Smart Relay User's Manual, Nov 2005, Schneider Electric Com. Page(s): 17-38.

[5] Siva Kumar a/l Subramaniam, Siti Huzaimah binti Husin, Yusmarnita binti Yusop and Abdul Hamid bin Hamidon, 2007, Real time mailbox alert system via sms or email, Asia - Pacific Conference on Applied Electromagnetism (APACE 2007), 4- 6 December 2007, Paper number: APACE165.

[6] Zelio Logic 2 SR2COM01 Communications Interface Help for using the operations folder Nov 2005,

[9] Geoffrey Strokes, Handbook of Electrical Installation Practice, $4^{\text {th }}$ Edition, 2003, Blackwell Science Ltd., Page(s): 1-10.

[10] Trevor Linsley, Introduction to Electrical Installation Work, 2007, Elsevier Ltd., Page(s): 197-211.

[11] Siti Huzaimah Husin, Saravana Kumar Soorinarayanan, Yusmarnita Yusop, Siva Kumar Subramanaiam and Zulhairi Othman, 2008, Smart Switching System, $3^{\text {rd }}$ International Conference on Postgraduate Education, 16-17 December 2008.

[12] Siva Kumar a/l Subramaniam, Siti Huzaimah binti Husin, Yusmarnita binti Yusop and Abdul Hamid bin Hamidon, 2009, Mail Compartment Alert System via SMS or E-mail, Proceedings of the Seminar Pencapaian Peyelidikan UTEM 2008 (REACH '08), 3-4 December 2008, Page(s): 71-74.

[13] L.Doulos, A.Tsangrassoulis and F.V. Topalis, 2007, Evaluation of Lighting Controls in Office Buildings, $6^{\text {th }}$ WSEAS International Conference on Circuits, Systems, Electronics, Control \& Signal Processing, 29-31 December 2007, Page(s): 69-77.

[14] Mohd Hilmi Hassan, Emy Elyanee Mustapha and Halif Ridzuan Baharuddin, 2009, Mobile University Notification System : A jabber- based Notification System for Education Institutions, Proceedings of the $8^{\text {th }}$ International Conference on Applications of Electrical Engineering, 30 April - 2 May 2009, Page(s): 64-69.

[15] M.H. Hasan, Z. Sulaiman, N.S. Haron and A.F. Mustaza, 2007, Enalbling Interoperability Between Mobile IM and Different IM Applications Using Jabber, $11^{\text {th }}$ International Conference of Circuits, System, Communication and Computers, Crete 2007.

[16] Sharudin, Mohd S., 2007, Intelligent Aquaculture System via SMS, Universiti Teknologi Petronas, Malaysia.

[17] S. K. Subramaniam, S. H. Husin, S. A. Anas And A. H. Hamidon Multiple Method Switching System for Electrical Appliances using Programmable Logic Controller, Wseas Transactions On Systems And Control. 